\title{
A NOTE ON THE FORMATION OF ETCH PITS ON DEFORMED AgCl CRYSTALS
}

The formation of etch pits on dislocations in $\mathrm{AgCl}$ crystals was studied usingcrystals prepared by the adapted Hedges-Mitchell method [1]. Single crystal samples. of equal dimensions were cut from the $\mathrm{AgCl}$ plates and were annealed for four hours at a temperature of $390^{\circ} \mathrm{C}$ and for another four hours cooled to room temperature. The samples were deformed by tension or compression. The dislocations were rendered visible by etching with a $20 \%$ solution of $\mathrm{Na}_{2} \mathrm{~S}_{2} \mathrm{O}_{3}$ after [2]. The surface of the crystals approached - with larger or small deviations - the (001) plane. The maximum deviation found was $28^{\circ}$, the minimum $2^{\circ}$.

It could be deduced from the results that dislocations caused by plastic deformation can be etched by means of the above-mentioned etchant only on planes inclined from the (001) plane by less than $10^{\circ}$. Dislocations produced at crystal growth were etched up to an inclination of $25^{\circ}$. In samples with an inclination larger than $25^{\circ}$ no etch. pits were formed.

Figure $1 \mathrm{a}^{1)}$ represents the etch pits of a crystal with its surface inclined by $2^{\circ}$ from: the (001) plane. The sample was deformed by the impact of a ball $1.5 \mathrm{~mm}$ in diameter; the pressure developed was $0.3 \mathrm{~kg} / \mathrm{mm}^{2}$. Rows of dislocations were formed at. a distance of $0.5 \mathrm{~mm}$ from the edge of the indentation created by deformation.

The shape of the etch pits also depends on the orientation of the crystal surface. This can be seen by comparing the preceding figure with Fig. $1 b$; here the etch pits are on a surface inclined by $20^{\circ}$ from (001).

Analogical results were obtained by studying $\mathrm{AgCl}$ crystals doped with 0.01 mol. $\% \mathrm{CdCl}_{2}$. Here an interesting and typical effect was observed: the impurity became denser in bands of smaller or larger width with a relatively constant distance (Fig. 1c).

Received 31. 1. 1963.

A. Dordová

Matematicko-fyzikálni fakulta. Karlova university, Praha*)

*) Now: Katedra fyziky stavební fakulty ČUT, Praha.

1) For all Figs. see Appendix II (p. 702b).

\section{References}

[1] Hedges J. M., Mitchell J. W.: Phil. Mag. 44 (1953), 357.

[2] Jones D. A., Mitchell J. W.: Phil. Mag. 2 (1957), 1047. 
Appendix II.: Dordová A.: A Note on the Formation of Etch Pits on Deformed AgCl Crystals (p. 699).

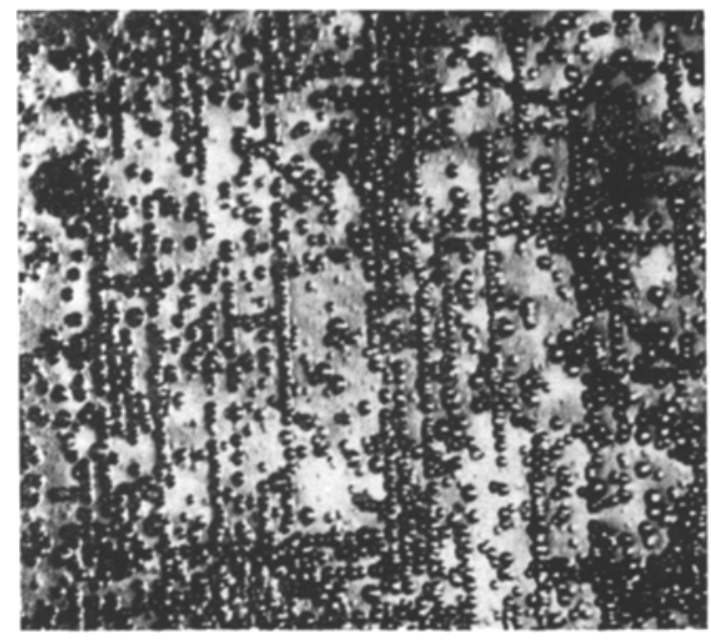

Fig. 1a. Rows of dislocations produced in $\mathrm{AgCl}$ crystal after deformation. Magnification $175 \times$.

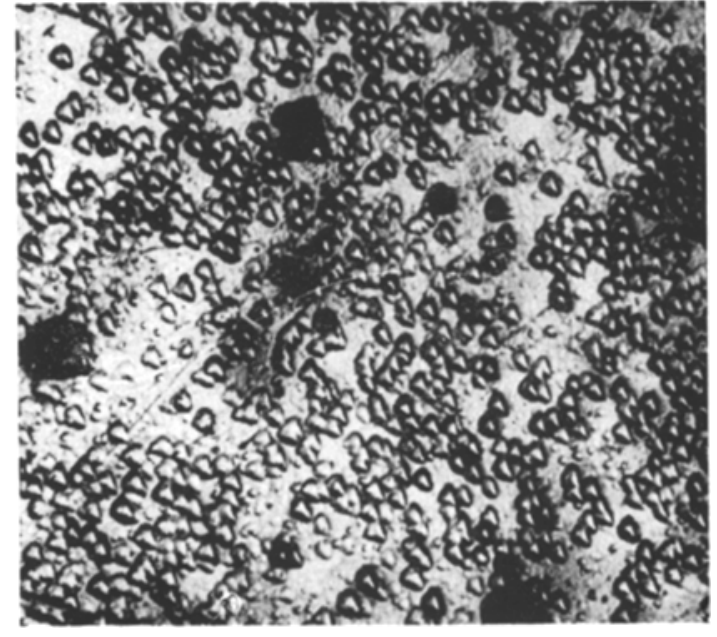

Fig. 1b. Etched surface of AgCl sample after $0.35 \%$ deformation by elongation. Magnification $175 \times$.

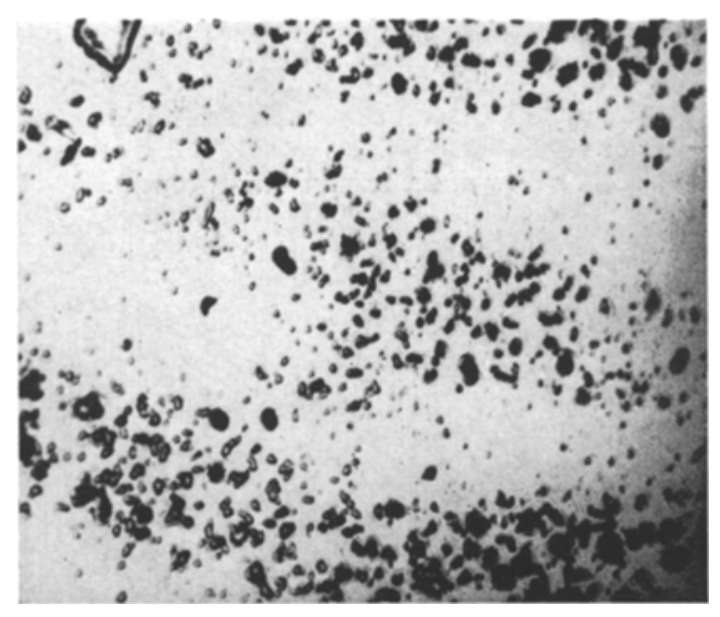

Fig. 1c. Unetched surface of $\mathrm{AgCl}$ crystal doped with $0.01 \mathrm{~mol} \% \mathrm{CdCl}_{2}$. Magnification $175 \times$. 